\title{
QUALIDADE FÍSICO-QUÍMICA E SENSORIAL DE OVOS DE GALINHAS SUBMETIDOS A TRATAMENTO SUPERFICIAL DA CASCA ARMAZENADOS SOB REFRIGERAÇÃO
}

Hallef Rieger Salgado ${ }^{1}$, Michele de Oliveira Mendonça², Glenda Roberta Silva Moura ${ }^{3}$, Gabriela dos Santos Madella ${ }^{4}$, Filipe Lima Bastos ${ }^{4}$, Iolanda Silveira Freitas ${ }^{4}$, Vanessa Riani Olmi Silva ${ }^{5}$

\begin{abstract}
RESUMO - Objetivou-se avaliar a qualidade físico-química e sensorial de ovos de galinha, mantidas sob piso, tratados superficialmente com óleo mineral, gelatina sem sabor a $6 \%$ e soluções de própolis ( 15 e $20 \%$ ) estocados sob refrigeração (Incubadora B.O.D: $7,9^{\circ} \mathrm{C}$ e 41,9\% de umidade relativa). Para o experimento de qualidade físico-química, realizou- se um delineamento inteiramente casualizado em esquema fatorial 5 x 5 (sem tratamento; própolis $15 \%$; própolis $20 \%$; gelatina a $6 \%$ e óleo mineral, durante cinco semanas de estocagem) com seis repetições de quatro ovos cada. Foram avaliados: perda de peso dos ovos (\%); peso específico dos ovos ( $\mathrm{g} /$ $\mathrm{cm}^{3}$ ); unidades Haugh; peso (g) e pH do albúmen; peso (g), pH, índice e cor da gema. O tratamento com óleo mineral seguido da gelatina e da solução de própolis a $15 \%$ promoveu proteção contra a perda progressiva de peso e diminuição do peso específico e das unidades Haugh. Foram realizados testes de aceitabilidade de ovos com 14 e 28 dias para avaliação dos atributos: cor, aroma, sabor e impressão global, através de uma escala hedônica de 9 pontos. Não houve diferença significativa aos 14 dias de armazenagem, contudo aos 28 dias houve diferença significativa para os atributos cor, sabor e impressão global, com menores notas atribuídas aos ovos tratados com óleo mineral. A qualidade físico-química e sensorial dos ovos de galinhas, submetidos a tratamento superficial da casca por imersão com óleo mineral, gelatina sem sabor a $6 \%$ e própolis a $15 \%$ e a $20 \%$ são preservadas por cinco semanas de estocagem sob refrigeração.
\end{abstract}

Palavras chave: gelatina, óleo mineral, própolis.

\section{PHYSICOCHEMICAL AND SENSORIAL QUALITY OF HEN'S EGGS SUBMITTED TO SURFACE TREATMENT OF THE STORED UNDER REFRIGERATION}

\begin{abstract}
The objective of this study was to evaluate the physical-chemical and sensorial quality of chicken eggs, kept under the floor, treated with mineral oil, 6\% unflavored gelatin and propolis solutions (15 and $20 \%$ ) stored under refrigeration (BOD incubator: $7.9^{\circ} \mathrm{C}$ e $41,9 \%$ relative humidity). For the physico-chemical quality experiment, a completely randomized design was carried out in a $5 \times 5$ factorial scheme (no treatment, $15 \%$ propolis, $20 \%$ propolis, $6 \%$ gelatin and mineral oil for five weeks of storage) with six Repetitions of four eggs each. The following were evaluated: egg weight loss (\%); Specific weight of eggs ( $\left.\mathrm{g} / \mathrm{cm}^{3}\right) ; \mathrm{Haugh}$ units; Weight $(\mathrm{g})$ and $\mathrm{pH}$ of the albumen; Weight $(\mathrm{g}), \mathrm{pH}$, index and color of the yolk. Treatment with mineral oil followed by gelatin and 15\% propolis solution provided protection against progressive loss of weight and reduction of specific weight and Haugh units. Eggs were accepted for acceptance of eggs with 14 and 28 days to assess the attributes: color, aroma, flavor and overall impression, through a hedonic scale of 9 points. No significant difference was found for 14 days of storage, however at 28 da differences for color,
\end{abstract}

\footnotetext{
${ }^{1}$ Mestrando em Nutrição e Produção Animal-Universidade Federal de Viçosa-MG E-mail para correspondência: hallef_rieger@hotmail.com

${ }^{2}$ Docente do Departamento Acadêmico de Zootecnia - IF Sudeste MG/Campus Rio Pomba - MG.

${ }^{3}$ Mestranda em Nutrição e Produção Animal - IF Sudeste MG/Campus Rio Pomba - MG.

${ }^{4}$ Discente da Graduação em Zootecnia - IF Sudeste MG/Campus Rio Pomba - MG.

${ }^{5}$ Docente do Departamento Acadêmico de Alimentos - IF Sudeste MG/Campus Rio Pomba - MG.
} 
flavor and overall impression, were significative, with lower grades attributed to mineral oil treated. The physico-chemical and sensorial quality of hens eggs, submitted to surface treatment of the shell by immersion with mineral oil, $6 \%$ unflavored gelatin and $15 \%$ and $20 \%$ propolis, are preserved for five weeks under refrigerated storage.

Keywords: gelatin, mineral oil, propolis.

\section{INTRODUÇÃO}

Levantamentos feitos pela Associação Brasileira de Proteína Animal (ABPA) mostram que a produção brasileira de ovos totalizou no ano de 2015 cerca de 39,5 bilhões de unidades, recorde histórico que superou em $6,1 \%$ a produção registrada no ano anterior. Com o expressivo aumento da produção e o aquecimento do mercado interno, o consumo de ovos no Brasil em 2015 chegou a 191,7 unidades per capita, número 5,2\% superior ao obtido em 2014, que era de 182 ovos (ABPA, 2015).

O ovo é considerado um alimento de excelência na composição da dieta humana porque sua proteína é considerada de alto valor biológico. Por esta razão, o aumento do consumo de ovos e a utilização de seus benefícios nutricionais pela população dependem da qualidade do produto oferecido ao consumidor, determinada por um conjunto de características que podem influenciar o seu grau de aceitabilidade no mercado e agregar preço ao produto (Freitas et al., 2011).

Além disso, com as limitações impostas pela recente legislação em alguns países europeus em relação ao uso de gaiolas como sistema de produção de ovos de galinha, é crescente no Brasil a adoção da criação de galinhas poedeiras em piso, com a utilização de cama, o que possivelmente pode acelerar a perda de qualidade dos ovos, uma vez que os ovos postos diretamente na cama estão mais susceptíveis à entrada de bactérias, tendo que descartá-lo, resultando em prejuízos para o avicultor.

Além disso, como todos os produtos naturais de origem animal, o ovo também é perecível, e começa a perder seu valor nutricional momento após a postura e, sobretudo quando são expostos à métodos ineficazes de armazenamento, como verificado por Wardy et al. (2010).

O ovo está conservado convenientemente quando se mantêm inalterados seu sabor e valor nutritivo (Santos et al., 2009). Algumas pesquisas têm-se orientado na direção do uso de técnicas de tratamento que permitam prolongar o tempo de prateleira de ovos de galinha, através da utilização de revestimentos na casca (Silva et al., 2010)

Diversos métodos alternativos têm sido pesquisados, tais como o revestimento dos ovos com produtos naturais, como óleos essenciais e a própolis, por possuírem substâncias com efeitos antimicrobianos em sua composição química (Aygun et al., 2012).

Ao utilizar revestimentos como óleo mineral (Ryu et al., 2011), a própolis (Carvalho, 2009) e a gelatina sem sabor (Inamura, 2008) foi demonstrado aumento no tempo de prateleira dos ovos, preservando sua qualidade interna.

Dessa forma, este trabalho teve por objetivo avaliar a qualidade físico-química e sensorial de ovos de galinhas poedeiras semipesadas, mantidas sob piso, submetidos ou não a tratamento superficial na casca, armazenados por um período de até 35 dias sob refrigeração.

\section{MATERIAL E MÉTODOS}

O experimento foi realizado no setor de Avicultura do Instituto Federal de Educação, Ciência e Tecnologia do Sudeste de Minas Gerais, Campus Rio Pomba, do mês de março a abril de 2017, utilizando-se 1224 ovos, sendo 624 ovos para análises físico-químicas e 600 para análise sensorial, provenientes de poedeiras semipesadas da linhagem Hisex Brown ${ }^{\circledR}$, criadas em piso, no segundo ciclo de produção, após a muda forçada (124 semanas de vida).

Os ovos colhidos para condução da pesquisa foram provenientes de poedeiras alimentadas com ração única desde o início da postura (Tabela 1).

Para as análises físico-químicas, foram selecionados 624 ovos íntegros individualmente identificados e pesados e mantidos em ambiente refrigerado, 24 ovos foram utilizados para as determinações no tempo zero, e os outros 600 distribuídos e avaliados em delineamento experimental inteiramente casualizado em esquema fatorial $5 \times 5$, sendo os efeitos dos tratamentos com ovos sem 
Tabela 1 - Níveis de garantia dos nutrientes por quilograma de ração

\begin{tabular}{|c|c|c|}
\hline Nutriente & Quantidade & Unidade \\
\hline Umidade (Máximo) & 130,00 & $\mathrm{~g}$ \\
\hline Energia Metabolizável Aparente (Min) & $2.800,00$ & kcal \\
\hline Extrato Etéreo (Mínimo) & 25,00 & $\mathrm{~g}$ \\
\hline Proteína Bruta (Mínimo) & 180,00 & $\mathrm{~g}$ \\
\hline Lisina (Mínimo) & $8.000,00$ & $\mathrm{mg}$ \\
\hline Metionina (Mínimo) & $3.800,00$ & $\mathrm{mg}$ \\
\hline Matéria Fibrosa (Máximo) & 50,00 & $\mathrm{~g}$ \\
\hline Matéria Mineral (Máximo) & 150,00 & $\mathrm{~g}$ \\
\hline Cálcio (Mínimo/Máximo) & $38,00 / 40,00$ & $\mathrm{~g}$ \\
\hline Fósforo (Mínimo) & $5.500,00$ & $\mathrm{mg}$ \\
\hline Fósforo Disponível (Mínimo) & $4.800,00$ & $\mathrm{mg}$ \\
\hline Sódio (Mínimo) & $1.800,00$ & $\mathrm{mg}$ \\
\hline Cobre (Mínimo) & 8,00 & $\mathrm{mg}$ \\
\hline Ferro (Mínimo) & 32,00 & $\mathrm{mg}$ \\
\hline Iodo (Mínimo) & 1,00 & $\mathrm{mg}$ \\
\hline Manganês (Mínimo) & 80,00 & $\mathrm{mg}$ \\
\hline Selênio (Mínimo) & 0,30 & $\mathrm{mg}$ \\
\hline Zinco (Mínimo) & 66,00 & $\mathrm{mg}$ \\
\hline Vitamina A (Mínimo) & 7.000 & UI \\
\hline Vitamina D3 (Mínimo) & 1.750 & UI \\
\hline Vitamina E (Mínimo) & 7,00 & UI \\
\hline Vitamina B1 (Mínimo) & 0,50 & $\mathrm{mg}$ \\
\hline Vitamina B12 (Mínimo) & 6,00 & $\operatorname{mcg}$ \\
\hline Vitamina B2 (Mínimo) & 3,85 & $\mathrm{mg}$ \\
\hline Vitamina B6 (Mínimo) & 1,00 & $\mathrm{mg}$ \\
\hline Vitamina K3 (Mínimo) & 1,50 & $\mathrm{mg}$ \\
\hline Ácido Fólico (Mínimo) & 0,30 & $\mathrm{mg}$ \\
\hline Ácido Pantotênico (Mínimo) & 7,00 & $\mathrm{mg}$ \\
\hline Niacina (Mínimo) & 15,00 & $\mathrm{mg}$ \\
\hline Colina (Mínimo) & 300,00 & $\mathrm{mg}$ \\
\hline Pantotenato de Cálcio (Mínimo) & 5,85 & $\mathrm{mg}$ \\
\hline Bacitracina de Zinco & 25,00 & $\mathrm{mg}$ \\
\hline Fitase & 300 & FTU \\
\hline
\end{tabular}

tratamento superficial da casca; ovos que receberam tratamento superficial da casca com tintura de própolis a $15 \%$; ovos que receberam tratamento superficial da casca com tintura de própolis a $20 \%$; ovos que receberam tratamento superficial da casca com gelatina sem sabor a $6 \%$ e ovos que receberam tratamento superficial da casca com óleo mineral, avaliados em cinco tempos de armazenamento $(7,14,21,28$ e 35 dias $)$, sendo que cada tratamento foi composto de seis repetições com quatro ovos cada.

Todos os ovos utilizados nos respectivos tratamentos foram colhidos às $9 \mathrm{~h}$ da manhã e encaminhados para o Laboratório de Análise de Ovos para a seleção, a identificação e a realização do revestimento superficial e, então, estocados sob refrigeração.
Os ovos do tratamento com própolis (15 e 20\%) foram envernizados por imersão rápida (um minuto) com tintura de própolis a $15 \%$ ( $85 \%$ de álcool de cereais; $15 \%$ de própolis) e $20 \%$ ( $80 \%$ de álcool de cereais; $20 \%$ de própolis).

Os ovos do tratamento com óleo mineral foram imersos por um minuto em recipiente com óleo mineral puro para consumo humano (Naturol, Farmax ${ }^{\circledR}$ ).

Os ovos do tratamento com gelatina sem sabor a $6 \%$ foram imersos por um minuto em recipiente com a solução preparada (6\% gelatina e $94 \%$ água potável).

Após a realização dos tratamentos superficiais na casca dos ovos de cada grupo (própolis, gelatina e óleo mineral), os ovos foram mantidos sobre peneiras 
plásticas para escorrer o excesso do produto durante 30 minutos, e em seguida colocados em bandejas de polpa de papelão identificadas, sendo então estocados em Incubadora B.O.D programada para $8^{\circ} \mathrm{C}$, e sendo registradas diariamente as temperaturas máximas e mínimas e umidade relativa do ar através de termohigrômetro digital.

Ao final de cada período de armazenamento foram avaliados: perda de peso dos ovos (\%); peso específico dos ovos $\left(\mathrm{g} / \mathrm{cm}^{3}\right)$; unidades Haugh; porcentagem e pH do albúmen; porcentagem, $\mathrm{pH}$, índice e cor da gema, segundo a metodologia descrita por Oliveira \& Oliveira (2013).

A perda de peso durante a estocagem foi determinada pela diferença entre o peso de cada ovo no início e no final do tempo de armazenagem através de balança com precisão de $0,001 \mathrm{~g}$. Logo após a pesagem, o peso específico dos ovos foi determinado através da imersão dos ovos em soluções salinas com densidade variando de 1,055 a $1,090 \mathrm{~g} / \mathrm{cm}^{3}$, com intervalos de $0,005 \mathrm{~g} / \mathrm{cm}^{3}$, devidamente calibradas por meio de um densímetro $\left(\mathrm{OM}-5565\right.$, Incoterm $\left.^{\mathrm{O}}\right)$.

Imediatamente após a imersão dos ovos nas soluções citadas anteriormente, os ovos foram quebrados e feita à medição da altura do albúmen denso, com o uso de um paquímetro digital (DIGIMESS ${ }^{\circ}$ ) com precisão de $0,01 \mathrm{~mm}$, para posterior cálculo das unidades Haugh $[\mathrm{UH}=100$ * $\left.\log \left(\mathrm{h}+7,57-1,7 \mathrm{~W}^{0,37}\right)\right]$; onde $\mathrm{UH}=$ Unidades Haugh; $\mathrm{h}=$ altura do albúmen $(\mathrm{mm}) ; \mathrm{e} \mathrm{W}=$ peso do ovo $(\mathrm{g})$.

Logo após a determinação da altura do albúmen, foi mensurada a altura, o diâmetro e a cor da gema. O Índice Gema (IG) foi obtido através da fórmula: IG = altura da gema/diâmetro da gema, sendo que para determinar a altura e a largura da gema foi utilizado um paquímetro digital (DIGIMESS ${ }^{\circ}$ ).

A cor de cada gema in natura foi visualmente comparada e classificada pelos mesmos três julgadores em cada dia de avaliação pelo método subjetivo por meio do abanico colorimétrico da DSM ${ }^{\circledR}$, antiga Roche. Este leque contém 15 tons de amarelo, padronizados, e que pode ser utilizado para avaliar de forma comparativa a cor das gemas, sendo de número 1 amarelo mais pálido e o 15 alaranjado mais intenso (Sandeski, 2013). Cada valor de intensidade de pigmentação da gema correspondeu à média dos três valores mencionados pelos julgadores das gemas avaliadas individualmente.
Fez-se a separação entre a gema e o albúmen, a gema foi pesada, obtendo a porcentagem de gema em relação peso do ovo e em seguida a medição do pH.

O peso do albúmen foi obtido entre a diferença do peso do ovo menos o peso da gema mais o peso da casca, sendo este obtido após a lavagem das cascas e secagem em estufa de ventilação forçada à $60^{\circ} \mathrm{C}$ durante 24 horas.

As quatro gemas e os quatro albumens, correspondentes a cada repetição, foram agrupados em um béquer sendo realizada a análise do $\mathrm{pH}$ de cada componente por meio do peagâmetro (PHTEK PHS$\left.3 \mathrm{~B}^{\circledR}\right)$.

Os dados obtidos de cada parâmetro avaliado foram submetidos a análises estatísticas utilizando-se o programa SISVAR (Ferreira, 2014). Foi realizada análise de variância usando um modelo incluindo os efeitos do tempo de estocagem, do tratamento superficial da casca e da interação entre esses fatores. Onde houve interação significativa $(\mathrm{p}<0,05)$, foi feito o desdobramento do efeito do tempo de estocagem, em cada tratamento superficial da casca, por meio de regressão linear e quadrática, conforme melhor ajuste obtido para cada parâmetro. Não tendo ocorrido interação significativa ( $p>0,05)$, como o tempo de estocagem é uma variável contínua, foi feita análise de regressão, obtendo a curva que descrevesse melhor o comportamento dos dados. As médias do tratamento superficial da casca dos ovos ao longo do tempo de estocagem foram comparadas pelo teste Tukey a 0,05 de probabilidade.

Com a finalidade de verificar a influência dos tratamentos superficiais na casca dos ovos de galinha sobre a aceitação sensorial, foram selecionados 600 ovos e realizados dois testes de aceitabilidade, com ovos tratados ou não superficialmente na casca armazenados sob refrigeração por 14 e 28 dias. Foram determinados esses dois tempos de armazenamento em função do prazo máximo estabelecido pela Resolução No 35 da Agência Nacional de Vigilância Sanitária (ANVISA, 2009) para o consumo de ovos de galinha (30 dias sob refrigeração).

Antes da realização dos testes sensoriais, o projeto foi aprovado pelo Comitê de Ética de Pesquisa com Seres Humanos (CAAE: 45747815.2.0000.5588).

Em cada teste sensorial, foi fornecida uma amostra de cada tratamento (sem tratamento superficial; 
tratamento superficial com própolis a $15 \%$; tratamento superficial com própolis a $20 \%$; tratamento superficial com gelatina sem sabor $6 \%$, e tratamento superficial com óleo mineral).

A aceitabilidade das amostras foi avaliada por 60 julgadores, maiores de 18 anos, de ambos os sexos, não treinados e recrutados voluntariamente (Termo de Consentimento Livre e Esclarecido - Anexo I), para avaliação dos atributos: cor, aroma, sabor e impressão global dos ovos, através de uma escala hedônica estruturada mista de 9 pontos (1-desgostei extremamente a 9-gostei extremamente) (Anexo II).

Os ovos correspondentes a cada tratamento foram cozidos durante dez minutos, tempo contabilizado a partir do início da ebulição da água e, em seguida, resfriados utilizando água corrente, descascados manualmente e cortados longitudinalmente, contendo cada parte clara e gema, conforme descrito por Moraes (1985).

Os resultados das análises sensoriais foram submetidos à análise de variância no programa SISVAR (Ferreira, 2014) e utilizou-se o teste de Tukey a 0,05 de probabilidade para detectar diferença entre as médias.

\section{RESULTADOS E DISCUSSÃO}

As temperaturas máximas e mínimas e umidade do ar registrada durante o período experimental estão apresentadas na Tabela 2. A temperatura e umidade relativa média ao longo das cinco semanas de avaliação foram, respectivamente, $7,9^{\circ} \mathrm{C}$ e $41,9 \%$.

Independentemente de ter recebido ou não tratamento superficial na casca, verificou-se que todos os ovos perderam peso significativamente $(\mathrm{P}<0,05)$ durante o período de estocagem sob refrigeração (Tabela 3 ).
A perda de peso mais drástica foi em ovos não submetidos a tratamento superficial, linear crescente, seguido do tratamento com gelatina e solução de própolis a 15\%. O tratamento superficial com óleo mineral conferiu menor perda de peso dos ovos, sendo o ponto de máxima perda atingido aos 24 dias de estocagem (Tabela 4).

Esses resultados corroboram com os encontrados por Mendonça et al. (2013), que ao revestirem ovos de codorna com própolis a $10 \%$ ou óleo mineral constataram perda linear do peso dos ovos ao longo de cinco semanas de estocagem sob refrigeração, contudo, a perda de peso foi mais acentuada naqueles ovos de codorna que não receberam tratamento na casca.

O peso específico dos ovos, em condição de refrigeração, apresentou melhor resultado para o tratamento com óleo mineral, isso pode estar ligado ao fato do produto ser mais eficiente em selar os poros das cascas, o que retardou a evaporação da água do albúmen fazendo com que houvesse menor perda de peso dos ovos e maior peso específico ao longo dos 35 dias de estocagem (Tabela 3 ).

A redução no peso específico ou gravidade específica pode estar relacionada com a perda de peso durante o armazenamento. Segundo Cherian et al. (1996), quando os ovos são armazenados por longos períodos, pode ocorrer redução do peso do ovo devido à perda de água.

De acordo com fórmula da densidade ( $\mathrm{d}=$ massa/ volume), densidade e massa são grandezas diretamente proporcionais e, dessa forma, quando ocorre decréscimo na massa, simultaneamente, ocorre decréscimo na densidade (BARBOSA et al., 2008). Consequentemente, a maior perda de massa dos ovos ao longo do período de armazenagem resultou em menor gravidade específica,

Tabela 2 - Temperatura mínima e máxima e umidade relativa registradas durante o período experimental (média \pm desvio padrão)

\begin{tabular}{cccc}
\hline \multirow{2}{*}{ Tempo (semana) } & \multicolumn{2}{c}{ Temperatura $\left({ }^{\circ} \mathrm{C}\right)$} & UmidadeRelativa (\%) \\
\cline { 2 - 3 } & Mínima & Máxima & $41,6 \pm 11,26$ \\
1 & $4,3 \pm 0,76$ & $19,9 \pm 2,59$ & $42,6 \pm 9,78$ \\
2 & $3,5 \pm 0,28$ & $10,1 \pm 0,50$ & $41,9 \pm 8,78$ \\
3 & $3,5 \pm 0,15$ & $10,2 \pm 0,78$ & $41,1 \pm 7,35$ \\
4 & $3,5 \pm 0,11$ & $9,7 \pm 0,78$ & $42,3 \pm 8,70$ \\
5 & $3,4 \pm 0,16$ & $11,0 \pm 0,75$ & \\
Média & 7,9 & 41,9 & \\
\hline
\end{tabular}


Tabela 3 - Parâmetros de qualidade físico-química de ovos de galinha, produzidos em ninho, sem tratamento superficial e tratados superficialmente na casca com solução de própolis a 15 e a $20 \%$, gelatina a $6 \%$ e óleo mineral armazenados sob refrigeração avaliados em diferentes períodos de estocagem

\begin{tabular}{|c|c|c|c|c|c|c|}
\hline \multirow{2}{*}{ Tratamento superficial da casca } & \multicolumn{5}{|c|}{ Tempo de estocagem (dias) } & \multirow{2}{*}{ Média } \\
\hline & 7 & 14 & 21 & 28 & 35 & \\
\hline & \multicolumn{5}{|c|}{ Perda de Peso (\%) } & \\
\hline Sem tratamento & 0,98 A d & $2,17 \mathrm{Ac}$ & $3,00 \mathrm{~A} \mathrm{~b}$ & $3,31 \mathrm{~A} \mathrm{~b}$ & $5,03 \mathrm{~A} \mathrm{a}$ & $2,90^{\mathrm{A}}$ \\
\hline Própolis a $15 \%$ & $0,48 \mathrm{AB} \mathrm{c}$ & $1,56 \mathrm{~A} \mathrm{~b}$ & 1,85 в в & $2,01 \mathrm{C} \mathrm{b}$ & 3,43 BC a & $1,86^{\mathrm{C}}$ \\
\hline Própolis a $20 \%$ & $0,65 \mathrm{AB} \mathrm{c}$ & $1,54 \mathrm{~A} \mathrm{~b}$ & $2,30 \mathrm{AB}$ a & $2,57 \mathrm{BC} \mathrm{a}$ & $3,00 \mathrm{c} \mathrm{a}$ & $2,01 \mathrm{BC}$ \\
\hline Gelatina & $0,76^{\mathrm{AB} \mathrm{d}}$ & $1,59 \mathrm{Ac}$ & 2,23 в bc & $2,89 \mathrm{AB} \mathrm{b}$ & 3,77 в а & $2,25^{\text {в }}$ \\
\hline Óleo mineral & 0,05 в в & 0,42 в аb & $0,58^{\mathrm{C} \text { ab }}$ & $0,86 \mathrm{D}$ a & $0,36^{\mathrm{D} a b}$ & $0,45^{\mathrm{D}}$ \\
\hline \multirow[t]{2}{*}{ Média } & 0,59 & 1,46 & 1,99 & 2,33 & 3,12 & $\mathrm{CV}=23,72$ \\
\hline & \multicolumn{5}{|c|}{ Peso específico $\left(\mathrm{g} / \mathrm{cm}^{3}\right)$} & \\
\hline Sem tratamento & 1,077 & 1,066 & 1,061 & 1,061 & 1,060 & 1,065 в \\
\hline Própolis a $15 \%$ & 1,079 & 1,071 & 1,068 & 1,068 & 1,061 & 1,069 в \\
\hline Própolis a $20 \%$ & 1,077 & 1,071 & 1,066 & 1,093 & 1,063 & $1,074 \mathrm{AB}$ \\
\hline Gelatina & 1,075 & 1,070 & 1,065 & 1,062 & 1,060 & 1,067 в \\
\hline Óleo mineral & 1,086 & 1,081 & 1,081 & 1,078 & 1,081 & $1,082 \mathrm{~A}$ \\
\hline \multirow[t]{2}{*}{ Média $^{(*)}$} & 1,079 & 1,072 & 1,068 & 1,072 & 1,065 & $\mathrm{CV}=1,37$ \\
\hline & \multicolumn{5}{|c|}{ Porcentagem de gema (\%) } & \\
\hline Sem tratamento & 26,53 & 28,10 & 27,89 & 29,10 & 27,98 & 27,92 A \\
\hline Própolis a $15 \%$ & 25,99 & 27,54 & 28,38 & 26,70 & 28,53 & 27,43 Ав \\
\hline Própolis a $20 \%$ & 27,62 & 27,38 & 28,14 & 29,17 & 28,71 & $28,21 \mathrm{~A}$ \\
\hline Gelatina & 26,29 & 27,08 & 27,82 & 27,97 & 27,76 & 27,38 АВ \\
\hline Óleo mineral & 26,14 & 26,15 & 26,78 & 26,25 & 27,96 & $26,66^{\text {в }}$ \\
\hline \multirow[t]{2}{*}{ Média $^{(* *)}$} & 26,51 & 27,25 & 27,80 & 27,84 & 28,19 & $\mathrm{CV}=4,63$ \\
\hline & \multicolumn{5}{|c|}{ Porcentagem de albúmen (\%) } & \\
\hline Sem tratamento & 64,06 & 62,61 & 62,95 & 61,62 & 62,13 & $62,67 \mathrm{BC}$ \\
\hline Própolis a $15 \%$ & 64,86 & 63,12 & 62,10 & 63,74 & 61,55 & $63,08{ }^{\mathrm{ABC}}$ \\
\hline Própolis a $20 \%$ & 63,06 & 63,289 & 62,39 & 61,07 & 58,91 & $61,74^{\mathrm{C}}$ \\
\hline Gelatina & 64,76 & 63,52 & 62,72 & 62,48 & 62,50 & $63,20 \mathrm{AB}$ \\
\hline Óleo mineral & 64,41 & 64,95 & 63,89 & 64,50 & 62,55 & $64,06^{\mathrm{A}}$ \\
\hline \multirow[t]{2}{*}{ Média $^{(* * *)}$} & 64,23 & 63,50 & 62,81 & 62,68 & 61,53 & $\mathrm{CV}=2,99$ \\
\hline & \multicolumn{5}{|c|}{ Unidades Haugh } & \\
\hline Sem tratamento & 71,56 в аb & $75,75 \mathrm{~A} \mathrm{a}$ & $69,38 \mathrm{c} \mathrm{b}$ & $67,57 \mathrm{c} \mathrm{b}$ & 67,44 в в & $70,34^{\mathrm{C}}$ \\
\hline Própolis a $15 \%$ & $80,49 \mathrm{~A}$ a & $78,83 \mathrm{~A}$ a & $70,86^{\mathrm{BC} \mathrm{bc}}$ & 76,02 в аb & 69,37 в с & 75,11 в \\
\hline Própolis a $20 \%$ & $78,74 \mathrm{~A} \mathrm{ab}$ & $78,83 \mathrm{~A} \mathrm{a}$ & 71,86 вС с & 72,91 BC bc & 71,31 в с & 74,73 в \\
\hline Gelatina & $78,40^{\mathrm{A} a b}$ & 79,98 A а & $76,49 \mathrm{AB}$ ab & $78,64 \mathrm{AB}$ ab & 72,86 в в & 77,27 в \\
\hline Óleo mineral & 80,48 A a & $81,06 \mathrm{~A} \mathrm{a}$ & $80,21 \mathrm{~A}$ a & $82,24 \mathrm{~A} \mathrm{a}$ & 81,48 A a & $81,09^{\mathrm{A}}$ \\
\hline \multirow[t]{2}{*}{ Média } & 77,93 & 78,89 & 73,76 & 75,48 & 72,49 & $\mathrm{CV}=4,83$ \\
\hline & \multicolumn{5}{|c|}{ Índice de gema } & \\
\hline Sem tratamento & $0,379 \mathrm{~A} \mathrm{a}$ & $0,362 \mathrm{~A} \mathrm{a}$ & $0,364 \mathrm{~A}$ a & $0,362 \mathrm{AB}$ a & $0,357 \mathrm{~B}$ a & $0,365 \mathrm{C}$ \\
\hline Própolis a $15 \%$ & $0,378 \mathrm{~A} \mathrm{a}$ & $0,384 \mathrm{~A} \mathrm{a}$ & $0,368 \mathrm{~A} \mathrm{a}$ & $0,368 \mathrm{AB}$ a & $0,370 \mathrm{AB}$ a & $0,374 \mathrm{BC}$ \\
\hline Própolis a $20 \%$ & $0,392 \mathrm{~A} \mathrm{a}$ & $0,379 \mathrm{~A} \mathrm{ab}$ & $0,388 \mathrm{~A} \mathrm{ab}$ & $0,367 \mathrm{AB} a b$ & $0,361 \mathrm{~B} \mathrm{~b}$ & $0,377 \mathrm{AB}$ \\
\hline Gelatina & $0,375 \mathrm{~A} \mathrm{ab}$ & $0,371 \mathrm{~A} \mathrm{ab}$ & $0,362 \mathrm{~A} \mathrm{ab}$ & $0,354 \mathrm{~B} \mathrm{~b}$ & $0,382 \mathrm{AB}$ a & $0,369 \mathrm{BC}$ \\
\hline Óleo mineral & $0,378 \mathrm{~A} \mathrm{a}$ & $0,385 \mathrm{~A} \mathrm{a}$ & $0,389 \mathrm{~A} \mathrm{a}$ & $0,389 \mathrm{~A} \mathrm{a}$ & $0,396 \mathrm{~A} \mathrm{a}$ & $0,387 \mathrm{~A}$ \\
\hline Média & 0,380 & 0,376 & 0,374 & 0,368 & 0,373 & $\mathrm{CV}=4,55$ \\
\hline
\end{tabular}


Tabela 3 - Cont.

\begin{tabular}{|c|c|c|c|c|c|c|}
\hline \multirow{2}{*}{ Tratamento superficial da casca } & \multicolumn{5}{|c|}{ Tempo de estocagem (dias) } & \multirow{2}{*}{ Média } \\
\hline & 7 & 14 & 21 & 28 & 35 & \\
\hline & \multicolumn{5}{|c|}{ pH do albúmen } & \\
\hline Sem tratamento & $10,01 \mathrm{~A} \mathrm{a}$ & $9,62 \mathrm{~A} \mathrm{ab}$ & $9,67 \mathrm{~A} \mathrm{ab}$ & $9,29 \mathrm{~A} \mathrm{~b}$ & $9,70 \mathrm{~A} \mathrm{ab}$ & $9,66 \mathrm{~A}$ \\
\hline Própolis a $15 \%$ & $9,31 \mathrm{~B} \mathrm{~b}$ & $9,68 \mathrm{~A} \mathrm{ab}$ & $9,57 \mathrm{AB} a b$ & $9,57 \mathrm{~A} \mathrm{ab}$ & $9,78 \mathrm{~A} \mathrm{a}$ & $9,58 \mathrm{~A}$ \\
\hline Própolis a $20 \%$ & $9,87 \mathrm{~A} \mathrm{a}$ & $9,83 \mathrm{~A} \mathrm{a}$ & $9,52 \mathrm{AB}$ a & $9,65 \mathrm{~A}$ a & $9,80 \mathrm{~A} \mathrm{a}$ & $9,73 \mathrm{~A}$ \\
\hline Gelatina & $9,14 \mathrm{~B} \mathrm{~b}$ & $9,42 \mathrm{~A} \mathrm{ab}$ & $9,16 \mathrm{~B} \mathrm{~b}$ & $9,22 \mathrm{~A} \mathrm{ab}$ & $9,64 \mathrm{~A}$ a & $9,32 \mathrm{~B}$ \\
\hline Óleo mineral & $8,49 \mathrm{C} \mathrm{a}$ & $8,65 \mathrm{~B}$ a & $8,62 \mathrm{C} \mathrm{a}$ & $8,58 \mathrm{~B} \mathrm{a}$ & $8,63 \mathrm{~B} \mathrm{a}$ & $8,59 \mathrm{C}$ \\
\hline \multirow[t]{2}{*}{ Média } & 9,36 & 9,44 & 9,31 & 9,26 & 9,51 & $\mathrm{CV}=2,97$ \\
\hline & \multicolumn{5}{|c|}{ pH da gema } & \\
\hline Sem tratamento & $6,19 \mathrm{~A} \mathrm{a}$ & $6,20 \mathrm{~A} \mathrm{a}$ & $6,43 \mathrm{~A}$ a & $6,13 \mathrm{~A} \mathrm{a}$ & $6,23 \mathrm{AB}$ a & 6,24 \\
\hline Própolis a $15 \%$ & $6,12 \mathrm{~A} \mathrm{a}$ & $6,26 \mathrm{~A} \mathrm{a}$ & $6,25 \mathrm{~A} \mathrm{a}$ & $6,22 \mathrm{~A} \mathrm{a}$ & $6,34 \mathrm{~A} \mathrm{a}$ & 6,24 \\
\hline Própolis a $20 \%$ & $6,14 \mathrm{~A} \mathrm{a}$ & $6,09 \mathrm{~A} \mathrm{a}$ & $6,35 \mathrm{~A}$ a & $6,23 \mathrm{~A} \mathrm{a}$ & $6,37 \mathrm{~A} \mathrm{a}$ & 6,24 \\
\hline Gelatina & $6,33 \mathrm{~A} \mathrm{a}$ & $6,05 \mathrm{~A} \mathrm{a}$ & $6,21 \mathrm{~A} \mathrm{a}$ & $6,37 \mathrm{~A} \mathrm{a}$ & $6,32 \mathrm{~A} \mathrm{a}$ & 6,26 \\
\hline Óleo mineral & $6,27 \mathrm{~A} \mathrm{a}$ & $6,24 \mathrm{~A} \mathrm{a}$ & $6,24 \mathrm{~A} \mathrm{a}$ & $6,13 \mathrm{~A} \mathrm{a}$ & $5,89 \mathrm{~B} \mathrm{a}$ & 6,15 \\
\hline \multirow[t]{2}{*}{ Média } & 6,21 & 6,17 & 6,30 & 6,22 & 6,23 & $\mathrm{CV}=3,79$ \\
\hline & \multicolumn{5}{|c|}{ Cor da gema } & \\
\hline Sem tratamento & $6,35 \mathrm{~A} \mathrm{~b}$ & $6,92 \mathrm{~A} \mathrm{a}$ & $6,69 \mathrm{~A} \mathrm{ab}$ & $7,04 \mathrm{~A} \mathrm{a}$ & $6,87 \mathrm{~A} \mathrm{a}$ & 6,76 \\
\hline Própolis a $15 \%$ & $6,53 \mathrm{~A} \mathrm{a}$ & $6,86 \mathrm{~A} \mathrm{a}$ & $6,64 \mathrm{~A}$ a & $6,39 \mathrm{~B}$ a & $6,86 \mathrm{~A} \mathrm{a}$ & 6,66 \\
\hline Própolis a $20 \%$ & $6,36 \mathrm{~A} \mathrm{a}$ & $6,63 \mathrm{~A} \mathrm{a}$ & $6,72 \mathrm{~A}$ a & $6,71 \mathrm{AB}$ a & $6,75 \mathrm{~A} \mathrm{a}$ & 6,63 \\
\hline Gelatina & $6,56 \mathrm{~A} \mathrm{ab}$ & $6,74 \mathrm{~A} \mathrm{ab}$ & $6,88 \mathrm{~A} \mathrm{ab}$ & $6,42 \mathrm{~B} \mathrm{~b}$ & $7,06 \mathrm{~A} \mathrm{a}$ & 6,73 \\
\hline Óleo mineral & $6,26 \mathrm{~A} \mathrm{~b}$ & $6,85 \mathrm{~A} \mathrm{a}$ & $6,89 \mathrm{~A}$ a & $6,67 \mathrm{AB} a b$ & $7,04 \mathrm{~A} \mathrm{a}$ & 6,74 \\
\hline Média & 6,41 & 6,80 & 6,75 & 6,64 & 6,92 & $\mathrm{CV}=4,69$ \\
\hline
\end{tabular}

${ }^{(A-D)}$ Médias seguidas por letras maiúsculas diferentes nas COLUNAS diferem pelo teste de Tukey $(\mathrm{p}<0,05)$. ${ }^{(\mathrm{a}-\mathrm{b})}$ Médias seguidas por letras minúsculas diferentes nas linhas diferem pelo teste de Tukey $(\mathrm{p}<0,05) . \mathrm{CV}=$ Coeficiente de variação $(\%)$.

Perda de peso: $\mathrm{P}$ tratamento $=0,0000 ; \mathrm{P}$ tempo de estocagem $=0,0000 ; \mathrm{P}$ interação $=0,0000$

Peso específico: $\mathrm{P}$ tratamento $=0,0001 ; \mathrm{P}$ tempo de estocagem $=0,0068 ; \mathrm{P}$ interação $=0,4705$

Porcentagem de gema: $\mathrm{P}$ tratamento $=0,0001 ; \mathrm{P}$ tempo de estocagem $=0,0000 ; \mathrm{P}$ interação $=0,1494$

Porcentagem de albúmen: $\mathrm{P}$ tratamento $=0,0002 ; \mathrm{P}$ tempo de estocagem $=0,0000 ; \mathrm{P}$ interação $=0,3731$

Unidades Haugh: $\mathrm{P}$ tratamento $=0,0000 ; \mathrm{P}$ tempo de estocagem $=0,0000 ; \mathrm{P}$ interação $=0,0037$

Índice de gema: $\mathrm{P}$ tratamento $=0,0000 ; \mathrm{P}$ tempo de estocagem $=0,0853 ; \mathrm{P}$ interação $=0,0340$

$\mathrm{pH}$ albúmen: $\mathrm{P}$ tratamento $=0,0000 ; \mathrm{P}$ tempo de estocagem $=0,0051 ; \mathrm{P}$ interação $=0,0078$

$\mathrm{pH}$ gema: $\mathrm{P}$ tratamento $=0,4656 ; \mathrm{P}$ tempo de estocagem $=0,3279 ; \mathrm{P}$ interação $=0,0428$

Cor da gema: $\mathrm{P}$ tratamento $=0,4342 ; \mathrm{P}$ tempo de estocagem $=0,0000 ; \mathrm{P}$ interação $=0,0431$

${ }^{(*)}$ Peso específico $\left(\mathrm{g} / \mathrm{cm}^{3}\right): 1,0793-0,0004 \mathrm{x} ; \mathrm{R}^{2}=0,68 ; \mathrm{P}=0,0019$

${ }^{(* *)}$ Porcentagem de gema (\%): $26,3384+0,0562 \mathrm{x} ; \mathrm{R}^{2}=0,91 ; \mathrm{P}=0,0000$

${ }^{(* * *)}$ Porcentagem de albúmen (\%): 64,8167-0,0889 x; $\mathrm{R}^{2}=0,95 ; \mathrm{P}=0,0000$

independente se os ovos de galinha receberam ou não tratamento superficial na casca (Peso específico (g/ $\left.\left.\mathrm{cm}^{3}\right): 1,0793-0,0004 \mathrm{x} ; \mathrm{R}^{2}=0,68 ; \mathrm{P}=0,0019\right)$.

Melhores resultados $(\mathrm{p}<0,05)$ para índice de gema foram obtidos para ovos tratados com óleo mineral e própolis a $20 \%$, enquanto que o revestimento com gelatina apresentou efeito quadrático com ponto de mínima aos 21 dias e própolis a $15 \%$ foi intermediário, sendo o pior resultado verificado para o grupo de ovos sem tratamento (Tabela 3 e 4 ).

Desde que ocorre a ovoposição, o ovo vem perdendo qualidade, fazendo trocas gasosas internamente com o meio ambiente. Segundo Santos et al. (2009), a perda de água que ocorre no ovo em consequência da evaporação provoca um aumento progressivo da câmara de ar e, consequentemente, a diminuição da gravidade específica do ovo. Sendo assim, ovos que receberam os tratamentos superficiais na casca com óleo mineral, gelatina a $6 \%$ e própolis a 15 e $20 \%$ apresentaram melhores resultados, com menor perda de água, evitando o aumento da câmera de ar, o que contribuiu para que a qualidade interna dos ovos ficasse preservada. Isso demonstra a importância de se fazer tratamento superficial da casca nos ovos a fim de conservar a integridade e prolongar o tempo de prateleira dos mesmos. 
Tabela 4 - Equações de regressão dos parâmetros de qualidade físico-química de ovos de galinha, produzidos em ninho, sem tratamento superficial e tratados superficialmente na casca com solução de própolis a 15 e a $20 \%$, gelatina a $6 \%$ e óleo mineral armazenados sob refrigeração avaliados em diferentes períodos de estocagem

\begin{tabular}{|c|c|c|c|c|}
\hline Tratamentosuperficial da casca & Equação & $\mathrm{R}^{2}$ & $\mathrm{P}$ & Tempo (dias) \\
\hline & Perda de peso $(\%)$ & & & \\
\hline Sem tratamento & $0,1229+0,1321 x$ & 0,96 & 0,0000 & - \\
\hline Própolis a $15 \%$ & $-0,0386+0,0906 x$ & 0,90 & 0,0000 & - \\
\hline Própolis a $20 \%$ & $-0,4034+0,1674 x-0,0020 x^{2}$ & 0,99 & 0,0041 & 41 \\
\hline Gelatina & $0,0532+0,1046 x$ & 1,00 & 0,0000 & - \\
\hline \multirow[t]{2}{*}{ Óleo mineral } & $-0,66620+0,1133 x-0,0023 x^{2}$ & 0,84 & 0,0287 & 24 \\
\hline & Unidades Haugh & & & \\
\hline Sem tratamento & $75,2666-0,2345 x$ & 0,56 & 0,0004 & - \\
\hline Própolis a $15 \%$ & $82,6290-0,3579 x$ & 0,66 & 0,0001 & - \\
\hline Própolis a $20 \%$ & $80,9659-0,2969 x$ & 0,77 & 0,0004 & - \\
\hline \multirow[t]{2}{*}{ Gelatina } & $81,0018-0,1776 x$ & 0,51 & 0,0095 & - \\
\hline & Índice de gema & & & \\
\hline Sem tratamento & $0,3781-0,0006 x$ & 0,70 & 0,0111 & - \\
\hline Própolis a $20 \%$ & $0,3989-0,0010 x$ & 0,76 & 0,0048 & - \\
\hline \multirow[t]{2}{*}{ Gelatina } & $0,4015-0,0039 x+0,0001 x^{2}$ & 0,60 & 0,0181 & 21 \\
\hline & pH do albúmen & & & \\
\hline Própolis a $15 \%$ & $9,3338+0,0118 x$ & 0,56 & 0,0003 & - \\
\hline Própolis a $20 \%$ & $10,2293-0,0539 x+0,0012 x^{2}$ & 0,69 & 0,0001 & 23 \\
\hline \multirow[t]{2}{*}{ Gelatina } & $9,3773-0,0253 x+0,0009 x^{2}$ & 0,50 & 0,0040 & 15 \\
\hline & Cor da gema & & & \\
\hline Sem tratamento & $6,4069+0,0169 x$ & 0,46 & 0,0079 & - \\
\hline Óleo mineral & $6,3284+0,0197 x$ & 0,53 & 0,0007 & - \\
\hline
\end{tabular}

Para porcentagem de gema e de albúmen, os tratamentos com óleo mineral, gelatina a $6 \%$ e própolis a $15 \%$ proporcionaram menores valores comparados com própolis a $20 \%$ e sem tratamento, isso pode ser explicado pela minimização da perda de água através dos poros da casca, fechados após o tratamento superficial (Tabela 3). De acordo com Barbosa et al. (2008), o aumento e a diminuição de peso da gema e do albúmen com o tempo de estocagem podem ser atribuídos a transferência de água do albúmen para a gema. Isso confirma que os tratamentos óleo mineral, gelatina a $6 \%$ e própolis a $15 \%$ evitaram essa passagem da água para a gema. Corroborando com os resultados, Aygun et al. (2012) verificaram o mesmo efeito, menor perda de água em ovos de codornas pulverizados com solução de própolis a 5, 10 e 15\%.

$\mathrm{O}$ excesso de água na gema determina o aumento do seu volume, levando ao enfraquecimento da membrana vitelínica. Isto faz com que a gema pareça maior e achatada quando o ovo é observado em uma superfície plana após a sua quebra (Pissinati et al., 2014).
Para unidades Haugh, observou-se interação significativa $(p<0,05)$ entre os tratamentos superficiais e tempo de estocagem sob refrigeração (Tabela 3). Ovos tratados superficialmente na casca com óleo mineral apresentaram maiores valores de unidades Haugh, o tratamento com gelatina a $6 \%$ apresentou maior coeficiente angular da reta em comparação àqueles que receberam aplicação de própolis a 15 e a $20 \%$ apresentando valores intermediários de unidades Haugh, e sem tratamento foi constatado como sendo o pior resultado (Tabela 4). Isso demonstra, mais uma vez, a eficiência do óleo mineral em preservar a qualidade dos ovos durante a estocagem.

Segundo Caner (2005), as gemas têm uma faixa de $\mathrm{pH}(6,0$ a 6,5$)$ relativamente constante durante o armazenamento. O que foi observado no experimento, pois o $\mathrm{pH}$ das gemas manteve-se estável, em média, 6,2 por até 35 dias de estocagem sob refrigeração, não apresentando efeito significativo $(\mathrm{p}>0,05)$ entre os tratamentos (Tabela 3). Foi constatado por Andrade et al. (2009), que a cobertura com óleo mineral dos ovos 
de galinhas, provavelmente, evitou a perda de água e gás carbônico $\left(\mathrm{CO}_{2}\right)$ para o ambiente, mantendo os valores de $\mathrm{pH}$ estáveis.

A perda da qualidade interna do ovo ocorre normalmente em função da decomposição do ácido carbônico em gás carbônico e água. Como o gás carbônico é levado para o exterior em função da porosidade da casca do alimento, a água que permanece promove a liquefação do albúmen, provocando um aumento do $\mathrm{pH}$, levando a um processo de dissociação química do complexo proteico. Além do tamanho da câmara de ar aumentar, a gema também sofre alterações tornandose mais larga e tendo sua membrana enfraquecida (Rodrigues \& Salay, 2001). Assim, o pH do albúmen é o parâmetro mais utilizado para determinar a qualidade do ovo (Mota et al., 2017).

Para o $\mathrm{pH}$ do albúmen houve interação significativa $(p<0,05)$ entre os tratamentos (Tabela 3). O óleo mineral apresentou menor valor seguido da gelatina a $6 \%$ que apresentou efeito quadrático com ponto de mínima aos 15 dias (Tabela 4), isto indica que o selamento dos poros da casca promovido pela aplicação superficial com estas duas substâncias reduz a saída de $\mathrm{CO}_{2}$ do ovo, que é responsável pelo incremento do $\mathrm{pH}$ do albúmen ao longo do período de estocagem, assim como verificado com ovos de codornas por Mendonça et al. (2013). Já os demais tratamentos apresentaram maiores valores, o tratamento de própolis a $20 \%$ demonstrou efeito quadrático com ponto de mínima aos 23 dias (Tabela 4), o que indica que esse tratamento não foi tão eficiente em minimizar as perdas de $\mathrm{CO}_{2}$ através dos poros da casca, o que causou aumento do $\mathrm{pH}$ progressivamente ao passar das semanas de estocagem. Como consequência, os ovos podem, além de perder sua qualidade em decorrência das modificações determinadas pelo seu envelhecimento, podem sofrer também deterioração microbiana (Rodrigues \& Salay, 2001).

A tonalidade amarela da gema dos ovos não foi afetada pelo tratamento superficial na casca (Tabela 3 ), entretanto, apresentou interação significativa entre tempo de estocagem e ovos não tratados superficialmente e aqueles tratados com óleo mineral (Tabela 4). Esses tratamentos apresentaram intensificação linear da coloração da gema ao longo das cinco semanas de estocagem.

A pigmentação da gema pode variar de amarelo levemente claro a laranja escuro, de acordo com a alimentação e características individuais da galinha (Santos et al., 2009). Segundo Awang et al. (1992) e Hencken (1992), a cor da gema depende da presença de carotenoides na dieta das galinhas e quanto mais as aves consumirem alimentos que contenham pigmentos em sua composição tanto maior será a deposição destes nas gemas dos ovos e a intensidade da sua coloração. Assim, de certa forma, o tratamento superficial na casca não promoveu alterações significativas na coloração da gema dos ovos.

Não houve diferença significativa $(\mathrm{P}<0,05) \mathrm{em}$ nenhum atributo sensorial avaliado aos 14 dias de estocagem, os ovos foram avaliados pela escala hedônica estruturada mista de 9 pontos (1-desgostei extremamente; 9-gostei extremamente) e obtiveram nota entre 7 e 8 , o que significa que os provadores gostaram moderadamente e gostaram muito, ou seja, nenhuma das amostras foi recusada (Tabela 5).

Aos 28 dias de estocagem, detectou-se diferença significativa $(\mathrm{p}<0,05)$ para os atributos cor, sabor $\mathrm{e}$ impressão global (Tabela 5). Para todos os atributos sensoriais foram atribuídas notas médias acima de 6,0, o que indica, assim como para os ovos estocados por 14 dias, a aceitação de ovos de galinha submetidos a diferentes tratamentos superficiais.

Neste estudo, observou-se que o tratamento superficial com óleo mineral contribuiu significativamente $(\mathrm{p}<0,05)$ para a manutenção da qualidade físico-química dos ovos (Tabela 3 e 4), através do selamento eficiente dos poros da casca, manteve estável o pH do albúmen e retardou a perda de peso e o aumento progressivo da câmara de ar, o que dificultou o descasque dos ovos, pois a membrana da casca ficou aderida fortemente à casca. Desta forma, o ovo cozido apresentou deformidades e gerou atribuição de notas mais baixas nas características sensoriais, especialmente para a impressão global aos 28 dias de estocagem (Tabela 5).

No que diz respeito ao armazenamento do ovo, alguma deterioração em odor e sabor podem ocorrer, pois odores desagradáveis podem ser absorvidos pelos ovos, se não houver cuidado de evitar sua ocorrência durante a estocagem (Griswold, 2000). O odor e o sabor azedo característico aparecem, possivelmente, de acordo com Scatolini-Silva et al. (2013), pelas modificações que ocorrem na proteína e na gordura do ovo ao longo do período de armazenamento. 
Tabela 5 - Valores médios para os atributos: cor, aroma, sabor e impressão global (1-desgostei extremamente; 9-gostei extremamente) de ovos de galinha, produzidos em ninho, sem tratamento e tratados superficialmente na casca com solução de própolis a 15 e a $20 \%$, gelatina a $6 \%$ e óleo mineral armazenados sob refrigeração avaliados em diferentes períodos de estocagem

\begin{tabular}{|c|c|c|c|c|c|c|c|c|}
\hline \multirow[b]{2}{*}{ Atributos } & \multicolumn{8}{|c|}{14 dias } \\
\hline & $\begin{array}{c}\text { Sem } \\
\text { tratamento }\end{array}$ & $\begin{array}{c}\text { Própolisa } \\
15 \%\end{array}$ & $\begin{array}{c}\text { Própolisa } \\
20 \%\end{array}$ & Gelatina & Óleo mineral & Valor P & CV (\%) & DMS \\
\hline Cor & 7,37 & 7,87 & 7,60 & 7,51 & 7,65 & 0,2525 & 18,68 & 0,6131 \\
\hline Sabor & 7,54 & 7,67 & 7,47 & 7,41 & 7,38 & 0,7544 & 19,37 & 0,6281 \\
\hline Aroma & 7,42 & 7,57 & 7,50 & 7,37 & 7,38 & 0,8965 & 18,77 & 0,6048 \\
\hline Impressão global & 7,59 & 7,70 & 7,53 & 7,24 & 7,46 & 0,2892 & 19,49 & 0,6325 \\
\hline \multirow[b]{2}{*}{ Atributos } & \multicolumn{8}{|c|}{28 dias } \\
\hline & $\begin{array}{c}\text { Sem } \\
\text { tratamento }\end{array}$ & $\begin{array}{c}\text { Própolisa } \\
15 \%\end{array}$ & $\begin{array}{c}\text { Própolisa } \\
20 \%\end{array}$ & Gelatina & Óleo mineral & Valor P & CV $(\%)$ & DMS \\
\hline Cor & 7,42 a & 7,35 a & 7,52 a & $7,10^{a b}$ & $6,71^{\mathrm{b}}$ & 0,0006 & 19,90 & 0,6160 \\
\hline Sabor & 7,41 ab & $7,25^{\mathrm{ab}}$ & 7,55 a & $7,33 \mathrm{ab}$ & $6,76^{\mathrm{b}}$ & 0,0047 & 21,07 & 0,6576 \\
\hline Aroma & 7,20 & 6,98 & 7,29 & 6,89 & 6,78 & 0,1141 & 21,15 & 0,6399 \\
\hline Impressão global & $7,36^{\text {a }}$ & 7,29 a & 7,69 a & 7,25 a & 6,47 b & 0,0000 & 20,12 & 0,6209 \\
\hline
\end{tabular}

(a-b) Médias seguidas por letras minúsculas diferentes nas linhas diferem pelo teste de Tukey $(\mathrm{P}<0,05)$.

$\mathrm{CV}=$ Coeficiente de variação $(\%)$.

DMS = Diferença mínima significativa.

Não foram constatados neste estudo alterações negativos nos atributos sensoriais, independente se os ovos foram submetidos ou não ao tratamento superficial na casca, o que implica inferir que a refrigeração dos ovos contribuiu consideravelmente para a conservação da qualidade sensorial.

\section{CONCLUSÃO}

A qualidade físico-química e sensorial dos ovos de galinhas poedeiras semipesadas da linhagem Hisex Brown ${ }^{\circledR}$, mantidas sob piso, submetidos a tratamento superficial da casca por imersão com óleo mineral, gelatina sem sabor a $6 \%$ e solução de própolis a $15 \%$ ou a $20 \%$ são preservadas por até cinco semanas de armazenamento em ambiente refrigerado.

\section{LITERATURACITADA}

ABPA - ASSOCIAÇÃO BRASILEIRA DE PROTEÍNA ANIMAL. Produção de ovos do Brasil cresce $6,1 \%$ e chega a 39,5 bilhões de unidades. Disponível em $<$ http://abpa-br.com.br/noticia/producaode-ovos-do-brasil-cresce-61-e-chega-a-395bilhoes-de-unidades-1550>. Acesso em 26 mai. 2017.
ANDRADE, E.L.; MARINO, E.G.; MARCHINI, F.T.; FERRARI, N.G.; ANDREO, N.; FILHO, R.S.F.; CAMARGO, T.C.M.; BRIDI, A.M.; FONSECA, N.A.N. Valor de $\mathrm{pH}$ e cor da gema de ovos de galinhas poedeiras armazenados em diferentes métodos e períodos. In: XIX Congresso Brasileiro de Zootecnia-ZOOTEC, 2009, Águas de Lindóia/ SP. Anais... FZEA/USP-ABZ, 2009.

ANVISA. Agência Nacional de Vigilância Sanitária. Resolução $\mathbf{N}^{0}$ 35, de 17 de Junho de 2009. Dispõe sobre a obrigatoriedade de instruções de conservação e consumo na rotulagem de ovos e dá outras providências. Disponível em: $<$ http:// portal.anvisa.gov.br/documents/33880/2568070/ res0035_17_06_2009.pdf/72add6d3-c538-4e03-88a1fb7d763113f $4>$. Acesso em 29 jun. 2017.

AWANG, I.P.R.; CHULAN, U.; AHMAD, F.B.H. Curcumin for upgrading skin color of broilers. Pertanika Journals, v.15, n.1, p.37-38, 1992.

AYGUN, A; SERT, D.; COPUR, G. Effects of propolis on eggshell microbial activity, hatchability, and chick performance in Japanese quail (Coturnix coturnix japonica) eggs.

Poultry Science, v.91, p.1018-1025, 2012. 
BARBOSA, N.A.A.; SAKOMURA, N.K.; MENDONÇA, M.O.; FREITAS, E.R.

FERNANDES, J.B.K. Qualidade de ovos comerciais provenientes de poedeiras comerciais armazenados sob diferentes tempos e condições de ambientes. ARS Veterinária, v.24, n.2, 127-133, 2008.

CANER, C. Whey protein isolate coating and concentration effects on egg shelf life.

Journal of the Science of Food and Agriculture, v. 85, n.13, p.2143-2148, 2005.

CARVALHO, J.X. Influência da própolis na vida de prateleira de ovos de galinha. Revista Brasileira de Agroecologia, v.4, n.2, p.718-720, 2009.

CHERIAN, G.; WOLFE, E. H.; SIM, J.S. Feeding dietary oil with tocopherols: effect of internal qualities of eggs during storage. Journal of Food Science, v.61, n.1, p.15-18, 1996.

FERREIRA, D.F. SISVAR: Guide for its Bootstrap procedures in multiple comparisons. Ciência e Agrotecnologia, v.38, n.2, p.109-112, 2014.

FREITAS, L.W.; ALMEIDA PAZ, I.C.L.; GARCIA, R.G.; CALDARA, F.R.; SENO, L.O.; FELIX, G.A.; LIMA, N.D.S.; FERREIRA, V.M.O.S.; CAVICHIOLO, F. Aspectos qualitativos de ovos comerciais submetidos a diferentes condições de armazenamento.

Revista Agrarian, v.4, n.11, p.66-72, 2011.

GRISWOLD, R.M. Estudos experimentais dos alimentos. Edgard Blugher. Handbook, n. 75,2000 .

HENCKEN, H. Chemical and physiological behavior of feed carotenoids and their effects on pigmentation. Poultry Science, v.71, n.4, p.711-717, 1992.

INAMURA, P.Y. Efeito da radiação gama sobre a viscosidade de soluções de gelatina e pectina utilizadas na indústria de alimentos. Dissertação (Mestrado em Ciências) - Instituto de Pesquisas Energéticas e Nucleares, autarquia associada à Universidade de São Paulo, São Paulo - SP, 2008, $78 \mathrm{f}$.
MENDONÇA, M.O.; REIS, R.S.; BARRETO, S.L.T.; MUNIZ, J.C.L.; VIANA, G.S; MENCALHA, R.; FERREIRA, R.C.; RIBEIRO, C.L.N. Qualidade de ovos de codorna submetidos ou não a tratamento superficial da casca armazenados em diferentes ambientes. Revista Brasileira de Saúde e Produção Animal, v.14, n.1, p.195-208, 2013.

MORAES, M.A.C. Métodos para avaliação sensorial dos alimentos. 5.ed. Campinas: Experimental, 1985. 85p.

MOTA, A.S.B.; LIMA, P.M.S.; SILVA, D.S.; ABREU, V.K.G.; FREITAS, E.R.; PEREIRA, A.L.F. Internal quality of eggs coated with cassava and yam starches. Revista Brasileira de Ciências Agrárias, v.12, n.1, p.47-50, 2017.

OLIVEIRA, B.L.; OLIVEIRA, D.D. Qualidade e tecnologia de ovos. Lavras: Editora UFLA (Universidade Federal de Lavras), 2013. 223p.

PISSINATI, A.O.A.; YAMASHITA, F.S.C.A.; PINHEIRO, J.W.; ROMAN, J.M.M. Qualidade interna de ovos submetidos a diferentes tipos de revestimento e armazenados por 35 dias a $25^{\circ} \mathrm{C}$.

Semina: Ciências Agrárias, v.35, n1, p.531-540, 2014.

RODRIGUES, K.R.M.; SALAY, E. Atitudes de granjeiros, atacadistas, varejistas e consumidores em relação à qualidade sanitária do ovo de galinha in natura. Revista de Nutrição, v.14, n.3, p.185-193, 2001.

RYU, K.N.; NO, H.K.; PRINYAWIWATKUL, W. Internal quality and shelf life of eggs coated with oils from different sources. Journal of Food Science, v.76, S325-S329, 2011.

SANDESKI, LÍGIA MARA. Otimização da pigmentação da gema do ovo. Dissertação (Mestrado) - Universidade Estadual Paulista. Faculdade de Medicina Veterinária, 2013.

SANTOS, M.S.V.; ESPÍNDOLA, G.B.; LÔBO, R.N.B.; FREITAS, E.R.; GUERRA, J.L.L.; SANTOS, A.B.E. Efeito da temperatura e estocagem em ovos. Ciência e Tecnologia de Alimentos, v.29, n.3, p.513-517, 2009.

SCATOLINI-SILVA, A.M.; BORBA, H.; GIAMPIETRO-GANECO, A.; LIMA, T.M.A.; DOURADO, R.C.; BERTON, M.P.; SOUZA, P.A. Características sensoriais de ovos armazenados em diferentes embalagens sob temperatura ambiente. Archivos de Zootecnia, v.62, n.240, p.543-553, 2013. 
SILVA, A.L.S.; BROLEZE, L.F.; SIDOU, L.F.; HENRIQUES, C.Y.H.; SPANOL, T.M.; AUGUSTO, P.E.D. Qualidade de ovos recobertos com fécula de mandioca. Tecnologia \& Ciência Agropecuária, v.4, n.3, p.43-46, 2010.
WARDY, W.; TORRICO, D.D.; NO, H.K.; PRINYAWIWATKUL, W.; SAALIA, F.K. Edible coating affects physic-functional properties and shelf life of chicken eggs during refrigerated and room temperature storage. International Journal of Food Science \& Technology, v.45, p.2659-2668, 2010.

Recebido para publicação em 31/1/2018 e aprovado em 2/6/2018. 